\title{
dx.doi.org/ Quando as mecânicas de jogo emergem das colônias de formigas'
}

\author{
Michelle Westerlaken ${ }^{2}$ \\ Tradução do inglês: Clayton Policarpo³
}

Resumo: Este trabalho contextualiza a pesquisa desenvolvida por Michelle Westerlaken, em 2016 , acerca da interação de formigas no design de jogos lúdicos. Na primeira parte do artigo, a autora defende a ludicidade como um atributo comum entre humanos e animais, e sugere dois caminhos possíveis para se pensar a participação dos animais no desenvolvimento de uma mecânica do jogo: o animal como parte do sistema e o animal como jogador. A segunda parte problematiza algumas das questões envolvidas no projeto e desenvolvimento de uma mecânica de jogo para entidades com as quais não nos relacionamos no contexto de interações lúdicas, como no caso das formigas. Por fim, são apresentadas as etapas de desenvolvimento e intercorrências que permearam o processo de criação de um jogo protagonizado pelos insetos.

Palavras-chave: Mecânica de jogo. Design de jogos. Jogos para animais. Formigas

I Translated with the permission of Transcript from Westerlaken, M. (20I8). When game mechanics come crawling out of ant colonies. In: Games and Rules Game Mechanics for the "Magic Circle", Beat Suter, Mela Kocher, René Bauer (eds.), Bielefeld, DE: Transcript Verlag, pp. 299-3I5, DoI: I0.I436I/9783839443040-0I6.

2 Michelle Westerlaken é pesquisadora e designer interdisciplinar. Possui PhD em Design de Interação pela Universidade de Malmö, Suécia. É pesquisadora associada no Departamento de Sociologia da Universidade de Cambridge. Mais informações disponíveis em: michellewesterlaken.com.

3 Doutorando e mestre em Tecnologias da Inteligência e Design Digital, puc-sp. Professor temporário da graduação em Artes Visuais, ECA-UsP. Integrante dos grupos Transobjeto (TIDD/PUC-SP) e Realidades (ECA-USP). cv Lattes: lattes.cnpq.br/880I492560768204. E-mail: clayton.policarpo@gmail.com. 


\section{When game mechanics come crawling out of ant colonies}

Abstract: This paper contextualizes a Michelle Westerlaken research, 20I6, about ant interactions in playful game designs. In the first part, Westerlaken defends playfulness as a common attribute between humans and animals, and suggests two ways to think about animal participation in the game mechanics: the animal as part of the system and the animal as player. The second part discusses some questions involved in the design and development of game mechanics for ants, entities which we don't frequently relate in the context of playful interactions. In the third part, the stages of game design development and some trouble in the process are presented.

Keywords: Game mechanic. Game design. Games for animals. Ants. 


\section{Introdução}

Os campos acadêmicos de estudos de jogos, etologia e antropologia argumentaram - em várias ocasiões e contextos - que a ludicidade não é uma atitude ou um modo de ser que é exclusivo dos seres humanos (HUIZINGA, I955 [I950]; BATESON, I987 [I972]; BuRGHARDT, 2006). A consciência desta qualidade abrangente de ludicidade pode ser facilmente detectada no número de brinquedos e jogos produzidos com base na crença de que outros seres humanos não são apenas sencientes, mas se expressam de uma maneira lúdica. Tomando a definição geral e amplamente utilizada de Miguel Sicart de mecânica de jogo como "métodos invocados por agentes para interagir com o mundo do jogo" (2008), podemos portanto dizer que esses agentes não têm necessariamente de ser humanos ou inteligências artificiais (IA) (como inicialmente alegado por Sicart), mas também podem ser animais. Na verdade, no campo da pesquisa de jogos, vários estudiosos têm investigado o design de artefatos lúdicos e jogos ${ }^{4}$ que envolvem animais. Seguindo a estrutura de Sicart para a análise da mecânica do jogo, e prestando atenção à maneira como os animais agem como agentes que se apropriam dessas mecânicas (em contextos lúdicos digitais e não digitais, com níveis variados de abstração), poderíamos dividir estes esforços em dois grupos diferentes: jogos que envolvem animais como parte do sistema de jogo e jogos que envolvem animais como jogadores intencionais.

4 Em vez de nos envolvermos no debate complexo e muitas vezes antropocêntrico sobre se os artefatos que envolvem animais como participantes se qualificam ou não como "jogos" de acordo com algumas definições do termo (ARJORANTA, 20I4), neste artigo, usarei o termo "artefatos lúdicos" para indicar uma ampla gama de objetos que incluem aqueles que podem implicar regras e resultados quantificáveis (SALEN; ZiMMERMAN, 2003), objetos semelhantes a brinquedos livremente apropriáveis (SICART, 20I4) e quaisquer outras formas híbridas através das quais os animais podem se expressar de uma maneira lúdica. O termo "lúdico", por sua vez, não se refere apenas a "brincar" como uma atividade que pode ser observada no comportamento animal (incluindo signos como, entre outros, lutas encenadas e movimentos exagerados em situações de baixo estresse) (BurghardT, 2006). Em vez disso, "lúdico", aqui, pretende indicar uma atitude ambígua e despretensiosa (self-effacing) que pode ser adotada pelo animal na interação com o artefato (Sicart, 20I4). Isso significa que a brincadeira em animais pode, por exemplo, surgir de compromissos relacionados a coisas como exploração, curiosidade, desafios cognitivos, comportamento destrutivo, criação de caos, compartilhamento de afetos, interação social ou experiências sensoriais prazerosas. E com referência a esses significados que os termos "artefatos lúdicos", "interações lúdicas”, "jogos", "brinquedos" e "brincadeira” são aqui usados. 


\section{Animais em sistemas}

Esta categoria envolve o tipo de jogos que dependem da inclusão (muitas vezes forçada) de animais como agentes. Esses jogos não são projetados para os animais, mas incorporam as suas interações com o sistema de jogo para permitir a jogabilidade e/ou exibição para humanos. Esse fenômeno pode ser observado em um projeto em que pesquisadores e designers construíram uma simulação do jogo Pac-Man em que jogadores humanos podiam jogar contra grilos reais que representam os fantasmas do jogo (LAMERS; VAN ECK, 2OI2). Outro exemplo inclui um redesenho do jogo Pong em que a IA é realizada por uma barata que carrega um pixel em seus ombros (SAVICIC 2005). Abordagens mais parecidas com brinquedos para essa inclusão forçada de animais incluem estimulação elétrica artificial para controlar os movimentos de baratas (Tне RовоRоACH KICKSTARTER). Em alguns outros casos, o animal recebe controle sobre o sistema interativo, como o sistema robótico experimental de Garnet Hertz, no qual os movimentos corporais de uma barata são traduzidos na locomoção física de um robô de três rodas (HERTZ, 2008) e um sistema que rastreia o movimento de um peixinho dourado, transmitido através de um vídeo online, que gera input para um jogo Pokémon (CunNinGHAM, 20I4). Embora o nível de controle do animal sobre o artefato seja diferente em cada um desses exemplos, os sistemas de jogo são todos projetados para o envolvimento ou diversão humana e geralmente não levam os desejos e necessidades do animal em consideração (além daqueles que são necessários para o funcionamento do sistema de jogo ou interação com o artefato). Pode-se argumentar que, na maioria dos casos, o animal pode não estar ciente de seu envolvimento nos artefatos lúdicos. Dentro da definição de Sicart de mecânica de jogo, a agência do animal nestes contextos pode, portanto, ser melhor comparada à de uma IA com um espaço de possibilidade limitado para interagir com o sistema de jogo/ brinquedo e com o propósito de contribuir para a experiência (humana) do jogador. Com a importante diferença de que, em vez de entidades de IA programadas por humanos, agora sabemos que esses animais são criaturas sencientes capazes de sofrer angústia e, portanto, pode-se argumentar que esses tipos de jogos e brinquedos contribuem para uma opressão animal e um especismo. ${ }^{5}$

5 "Especismo" é um termo que é trazido à atenção pelo campo dos estudos críticos com animais e se refere à atribuição de valores e direitos a indivíduos apenas com base em sua pertença à espécie. O termo apareceu pela primeira vez em um panfleto de Richard D. Ryder em I970 que foi usado para protestar contra a experimentação animal (cf. SINGER, 2015 [I975]). Análogo à discriminação com base na raça (racismo) ou sexo (sexismo), o especismo tem características intersetoriais com outras formas de opressão e segue um padrão semelhante ao permitir que o interesse de uma espécie (geralmente o humano) se sobreponha aos interesses de outra (geralmente espécies não humanas; cf. ibid.). 


\section{Animais como jogadores}

Uma abordagem que é potencialmente menos opressiva para o envolvimento de animais em artefatos lúdicos inclui experiências como jogadores em interfaces projetadas para animais. Nesse caso, os designers estão interessados na maneira como os animais desfrutam de certas atividades e em como se expressam de maneira lúdica, de forma que buscam desenvolver sistemas lúdicos capazes de mediar esses tipos de interações. Alguns exemplos incluem projetos conduzidos com protótipos de jogos de tela de toque para orangotangos em abrigos (WIRMAN, 20I4), um conceito de videogame que permite que humanos e porcos de criação joguem juntos (Driessen et al., 20I4), um protótipo de jogo de Tablet para humanos e gatos domésticos (WeSterlaken; Gualeni, 20I4) e protótipos que exploram brinquedos interativos para elefantes em cativeiro (FRENCH, 20I5). Nestes exemplos, em vez de reduzir os animais a agentes dentro dos sistemas, a mecânica do jogo e a acessibilidade permitem que os próprios animais "se apropriem da ação dentro do mundo do jogo [ou contexto lúdico] e se comportem de maneiras imprevisíveis" (SICART, 2008, p. 3). Como um campo de pesquisa dentro do design de jogos, o reconhecimento do design de jogos para animais é bastante recente e requer uma abordagem diferente das estruturas que são utilizadas para analisar e projetar jogos para humanos. Não há práticas indicadas, diretrizes que são geralmente aceitas, livros didáticos ou listas de mecânica de jogos existentes e interações lúdicas para cada animal. O que todos esses exemplos têm em comum é a sua abordagem provisória e iterativa para criar jogos e artefatos lúdicos que colocam os animais envolvidos no centro do processo de design. Os animais são vistos como actantes influentes durante as diferentes fases do processo de design, bem como fatores na avaliação das implicações éticas dos resultados (WeSTERLAKEn; GuALEN I 20I6). Nesse contexto, o engajamento com os animais é definido por práticas contínuas para o desenvolvimento de novos insights e sensibilidades que definem as formas pelas quais as decisões projetuais são tomadas, ao tempo que as relações entre os humanos e animais envolvidos são continuamente remodeladas por meio de encontros não programados. Orangotangos esfregando a tela sensível ao toque com alimentos e fluidos corporais (WIRMAN; JÖRGENSEN 2OI5), elefantes destruindo mangueiras (FrENCH, 2OI5) e leitões seguindo luzes de laser (DriESSEN et al. 20I4) são apenas alguns exemplos desses insights inesperados que poderiam levam ao design de novas mecânicas de jogos e interações lúdicas. Trabalhando junto com animais como participantes do processo de design, 
logo fica claro que os designers são obrigados a adotar padrões flexíveis, receptividade e abordagens específicas ao contexto, que dificilmente seriam contempladas pela compreensão e pelas estruturas humanas já consolidadas na pesquisa em jogos.

\section{Projetando interações para outras entidades}

Ao adotar uma abordagem menos antropocêntrica para o design de jogos e interações lúdicas, argumento que esta segunda abordagem do envolvimento de animais em jogos (como jogadores) é mais respeitosa e atenciosa com a vida dos animais e, portanto, favorável à redução da agência animal a artefatos lúdicos como um meio para nossa própria diversão. O pesquisador Jason Hribal, especialista em Critical Animal Studies, também problematiza nossa tendência geral de ignorar a agência e a individualidade dos animais e argumenta que essa perspectiva, de modo desnecessário, entende os animais como seres estáticos ou como objetos desprovidos de qualquer "substância real" (Hribal, 2007, p. IO2). Hribal nos encoraja, em vez disso, a reconhecer e valorizar suas capacidades de responder e resistir às situações e mudanças (ibid.). No entanto, também poderia ser argumentado que o campo de pesquisa que inclui animais como jogadores até agora se concentrou apenas em mamíferos: animais que visivelmente adotam atitudes lúdicas semelhantes às dos humanos. Enquanto as abordagens mais centradas em sistemas parecem, até agora, estar focadas em animais que exibem um comportamento (lúdico) que é indiscutivelmente diferente dos seres humanos. Isso pode nos levar a questionar se há alguma limitação na maneira como projetamos jogos para animais como insetos, peixes ou répteis. É difícil nos relacionarmos ou nos identificarmos com animais que possuem modos distintos de experimentar o mundo no contexto dos jogos.

O antropólogo Eduardo Kohn assume uma postura ontológica mais comprometida e abrangente sobre a noção de diferença de espécies e as limitações morais que essas distinções implicam. Ele se concentra em identificar o que torna um processo "vivo" e argumenta que capacidades como aquelas de fazer escolhas, responder a estímulos e se adaptar a novas situações precisam ser moralmente contabilizadas, porque se continuarmos a ignorar essas aptidões em outras entidades, somos sempre forçados a recorrer às teorias centradas em formas humanas de representação e intencionalidade, como linguagem e raciocínio (ou formas de jogar) quando desejamos refletir sobre nossos compromissos com outras entidades (КоHN, 20I3). É nesse contexto básico, compartilhado e respon- 
sivo que as transformações e engajamentos (como reações, habilidade de resposta e "atenção" em relação às nossas intervenções de design) podem ocorrer. Usar essa lente teórica é particularmente útil, pois nos permite distinguir entidades que estão "vivas" (como uma barata ou um humano) de entidades que não estão (por exemplo, uma cadeira ou uma pedra, que não respondem e não se adaptam da mesma forma que as entidades vivas). Para ter certeza, de acordo com Kohn, essas entidades não são necessariamente parte do reino animal, nem mesmo precisam ser dotadas de um sistema nervoso para serem reconhecidas como "vivas" ou tendo um "self": de acordo com Kohn, plantas e cogumelos também se qualificariam (ibid.). Além disso, ele afirma que a percepção individual pode ser distribuída por vários corpos. É o caso, por exemplo, da "individualidade" de um seminário, uma multidão, uma floresta ou uma colônia de formigas (ibid.). Partindo da concepção de “self”, é possível entender e projetar para outras entidades com as quais podemos estabelecer uma relação de resposta e negociação, o que pode conduzir e moldar o design como uma atividade que é em si compartilhada. Na prática, isso significa que nós poderíamos tentar nos envolver em uma relação de design responsivo com plantas, bactérias, multidões e, possivelmente, até mesmo IA, porque poderíamos convidar essas entidades a participarem - e se adaptarem - à mecânica de jogo que projetamos, e interagir com os designers em um diálogo indexical. Em contraste, esses tais processos não poderiam ser alcançados da mesma forma com entidades não vivas, como tijolos, copos de papel e flocos de neve, porque essas coisas não respondem ativamente às mecânicas propostas. ${ }^{6}$

Neste artigo, desejo exemplificar as consequências desta estrutura para o design da mecânica de jogo para outras entidades que parecem ser muito diferentes de nós, mamíferos, ao discutir um projeto que visa desenvolver jogos para um animal com o qual todos estamos familiarizados, mas geralmente não nos relacionamos no contexto de interações lúdicas: Lasius niger, a formiga preta comum. Mais especificamente, no sentido de defender a inclusão de animais como jogadores em vez de agentes dentro dos sistemas, vou me concentrar na prática de projetar artefatos lúdicos

6 De uma perspectiva metafórica, pode-se sugerir que entidades não vivas, como os materiais que são usados em um processo de design, também são capazes de responder à maneira como são usados pelo designer, por exemplo, quando os materiais se quebram ou "resistem" a certos tipos de tratamento. Donald Schön rotulou isso como "back-talk", "um diálogo reflexivo com os materiais de uma situação" (SCHÖN, I987, p. 3I). No entanto, neste artigo, estou especificamente interessada nas sensibilidades e transformações que surgem no engajamento com entidades vivas que podem participar de maneira ativa e dinâmica dos processos de design. 
como uma atividade que pode transformar nossas relações com outras espécies e nossos preconceitos antropocêntricos. Com o experimento de design de jogo que irei explicar e refletir sobre, na terceira seção deste artigo, estou interessada em explorar cenários alternativos nos quais o especismo pode ser abordado criticamente e novas perspectivas sobre as várias e complexas relações entre animais e humanos podem ser reenquadradas e remodeladas.

Com esse objetivo em mente, é importante esclarecer que não estou interessada em produzir resultados acadêmicos na forma de construções científicas instrumentais que aspiram à validade e aplicabilidade universais. Mais especificamente, não estou preocupada em demonstrar a capacidade lúdica das formigas e usar isso como base para defender o design de jogos para formigas como jogadores. Em vez disso, pretendo me concentrar na ideia de Donna Haraway de "conhecimentos situados", como interpretações parciais e críticas de visões de mundo possíveis que permitem aberturas e negociações inesperadas com outras entidades (HARAWAy, I988). Seguindo esta atitude em relação ao envolvimento contextual com outras entidades, defendo o valor de prestar atenção a como o conhecimento local surge das práticas de design de jogos, conhecimentos que poderiam eliciar e acompanhar mudanças em nossas visões de mundo, no desenvolvimento da nossa sensibilidade e na forma como cuidamos do meio ambiente. Acredito que a noção de "conhecimentos situados" se encaixa particularmente bem com as abordagens experimentais e orientadas ao design com animais como uma forma de prefigurar e explorar futuros potenciais junto a outros seres. Com o objetivo de expandir a amplitude do nosso círculo moral para abraçar uma gama mais ampla de seres (agentes coessenciais ao planeta que habitamos e as intervenções que concebemos), gostaria de propor uma prática de design que pudesse ajudar-nos a negociar e repensar nossas relações com formigas (ou outros insetos). Junto a um grupo de alunos, eu me envolvi na prática de design de jogos para animais, a fim de especular sobre a ideia de criar interações lúdicas e mecânicas com as quais uma formiga poderia decidir - ou se recusar - a se envolver.

\section{Desafios do design com formigas}

O projeto experimental que descreverei e levarei em consideração para esta seção foi motivado e orientado pela seguinte questão: (como) podemos envolver efetivamente as formigas enquanto agentes ativos que podem se apropriar da mecânica do jogo, no processo de criação de um 
espaço lúdico ou de um jogo? O projeto durou um período de cinco meses e pode ser dividido em três fases diferentes: uma fase de trabalho de campo (I) em que tentei familiarizar-me com as formigas e os comportamentos dessa "identidade" alienígena, documentada através de métodos autoetnográficos (incluindo fotos, conversas e um diário de designer), uma fase de design (II) que consiste em uma short game jam com i6 designers de interação/jogos que desenvolveram diferentes protótipos, e uma fase de teste de jogo (III) em que as interações das formigas com cada um dos protótipos foram transmitidas ao vivo e refletimos como as formigas se apropriavam deles. Meu objetivo era usar práticas de design para gerar "conhecimentos situados" que poderiam encorajar transformações e sensibilidades entre os próprios designers, de modo a estimular novas ideias sobre o nosso relacionamento com essas formigas como "selves" que estariam incluídas em nosso horizonte moral. Além disso, este projeto nos permitiu questionar e reconfigurar nossa compreensão de como os “jogadores” são constituídos. Então, em vez de definir conceitos como "jogar" e "jogadores" como fundamentos a priori deste experimento, adotei uma abordagem de "pesquisa por meio do design", 7 onde dúvidas e reflexões emergentes proporcionaram a flexibilidade e o espaço filosófico para adotar novas perspectivas e sensibilidades tanto no jogo como na "individualidade" (selfhood) das formigas, e para responder às ações e os comportamentos das formigas em si.

Além disso, é importante destacar que esse processo, de forma alguma, foi organizado como um arranjo equânime ou não especista entre humanos e os animais envolvidos. As formigas que fizeram parte deste projeto foram obtidas por mim e (durante uma parte do processo) mantidas em cativeiro. Elas não tiveram a opção de sair desse processo. Isso significa que há um certo paradoxo aqui, que pode ser observado em todos os trabalhos de pesquisa existentes de "animais como jogadores", mencionados no início deste artigo: o design de artefatos lúdicos com o objetivo de melhorar a vidas de animais mantidos em cativeiro. Mesmo que as intenções desses projetos sejam melhorar as experiências de vida de animais individuais ou em geral expandir nossa consideração moral sobre os animais, os próprios projetos podem e devem ainda ser rotulados como "especistas", pois fazem parte de um sistema maior no qual opres-

7 Com o termo "pesquisa por meio do design", refiro-me a um campo acadêmico crescente que é caracterizado por contribuições de pesquisa em que os próprios processos de design e investigações práticas informam e investigam tópicos que são multiestáveis, complexos e orientados para o futuro (BUCHANAN, 2OOI; GAVER, 2OI2; LöWgREN; LARSEN; HOBYE, 2OI3). 
são e exploração animal são aceitas e normalizadas (cf. WESTERLAKEN, 20I6). Este paradoxo tem o potencial de contribuir para uma discussão mais ampla sobre até que ponto o objetivo de melhorar a vida dos animais em nosso planeta deve seguir abordagens que são mais "abolicionistas" (por exemplo, deveríamos evitar o especismo inteiramente e em todas as nossas ações) (WeISBERG, 2009), ou mais experimentais e práticas (por exemplo, repensar nossas relações com outras espécies exige que sujemos as mãos) (HaRaway, 20I6). Como esses tipos de reflexão fizeram parte do processo de pesquisa e da maneira como as decisões (de design) foram tomadas, voltarei a essa discussão na última seção. Por ora, é importante notar que essas observações e questões morais não devem ser ignoradas ou facilmente deixadas de lado, por mais insignificante e indigna que a vida de um pequeno inseto possa, inicialmente, parecer para nós, humanos. Assim que começarmos a nos envolver de maneira mais séria em suas vidas, eles sem dúvida causarão novos tipos de sensibilidade e responderão a nós de maneiras surpreendentes.

\section{Fase I: trabalho de campo, ou: vivendo com uma colônia de formigas}

$\mathrm{Na}$ primeira fase deste projeto, adquiri uma colônia de formigas pretas (incluindo uma rainha e I5 operárias) e montei um ambiente de moradia para elas em minha área de trabalho por um total de três meses. Esses ninhos de formigas estão disponíveis como produtos comerciais em diferentes tamanhos e configurações (vide Figura I). Como esperado, a introdução de uma colônia de formigas em um ambiente de escritório foi em si uma fonte de situações inesperadas e possibilidades para o desenvolvimento de "conhecimentos situados". A colônia de formigas tornou-se um assunto muito discutido entre os colegas, e as pessoas criaram o hábito de visitar meu escritório para ver o que as formigas estavam fazendo. Ao passar meu tempo com as formigas, naturalmente comecei a me preocupar com elas em um nível emocional, o que gerou uma mistura de dúvidas sobre os problemas éticos de mantê-las em cativeiro. Além disso, durante esses três meses, experimentei diferentes arranjos de moradia e pequenas intervenções de design para ver como as formigas reagiriam. Com base nessas experiências, listei uma gama de mecânicas de jogo centradas no jogador que poderiam inspirar o design de artefatos lúdicos e incluir interações como construir, deslizar, rastejar, quebrar, comer, arrastar, reunir, procurar e pular.

Então, um dia, as formigas conseguiram escapar de seu espaço de confinamento artificial, o que se tornou um dos eventos mais instigantes de todo o período. Sua história de fuga notável envolveu algumas formigas 
que encontraram uma pequena abertura entre duas paredes de acrílico de seu espaço de convívio, escaparam, juntaram alguns pedaços de papelão de uma fonte próxima e empilharam essas peças entre o acrílico para tornar a abertura maior e caminhar dentro e fora de forma mais confortável.
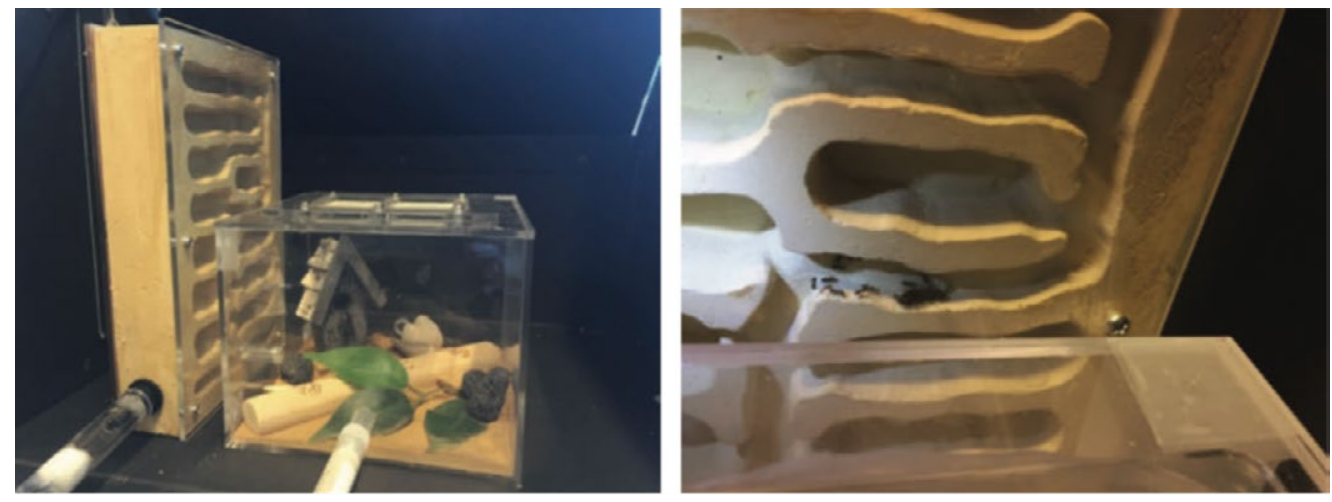

Figura I. O ambiente de convivência e confinamento das formigas (imagem à esquerda) consistia em um formigueiro de gesso com diferentes câmaras e uma área externa feita de acrílico transparente onde as formigas coletavam recursos e retiravam o lixo de seu ninho. Os tubos anexos fornecem água com açúcar. A imagem à direita mostra a formiga rainha, algumas das operárias e a parte (então colada) do acrílico por onde costumavam escapar. Fonte: autora.

Comecei então a refletir sobre como essa história de fuga poderia ser usada como um ponto de partida provocativo e especulativo para uma abertura no contexto de projeto que poderia inspirar designers a desenvolver desafios de escape rooms ${ }^{8}$ que poderiam ser jogados pelas formigas (independente de estarmos dispostos a aceitar as suas interações com os protótipos como uma expressão lúdica). Ao mesmo tempo, essa história de fuga e a estreita relação cotidiana com as formigas evocaram sentimentos de dúvida e crueldade que documentei em um diário:

“Alguns dias me sinto um pouco mal por estar em posse dessas formigas. [...] parecia que as formigas poderiam realmente se contentar com um cativeiro, porque elas têm todos os recursos de que precisam [...]. Mas quanto mais eu penso sobre essas coisas, mais eu sinto que sou de alguma forma cruel com elas, especialmente em relação à sua aventura de fuga e o bloqueio que fiz de sua saída (depois que elas colocaram tanto esforço na construção de sua rota de fuga) ou usando isso como uma ideia de como criar rotas de fugas nas quais nós, como humanos, estamos no controle de suas vidas de uma forma tão desigual.”

8 "Os escape rooms são jogos baseados em equipes de ação ao vivo, onde os jogadores descobrem pistas, resolvem quebra-cabeças e realizam tarefas em uma ou mais salas para cumprir um objetivo específico (geralmente escapar da sala) em um período de tempo limitado." (Nicholson, 20I5, p. I). 
Apesar dessas dúvidas, decidi continuar o projeto enquanto pensava sobre a dinâmica de poder e a desigualdade entre os humanos e os animais que estavam ali envolvidos. Neste ponto, eu queria saber se outras pessoas passariam por transformações semelhantes, acaso se envolvessem em um processo de design de jogo envolvesse formigas, de maneira semelhante.

\section{Fase II: design ou: desafios de escape rooms para formigas}

Com essa história de fuga como inspiração, uma game jam "escape rooms para formigas” foi organizada durante a conferência Student Interaction Design and Research (SIDeR) na Universidade de Malmö (Suécia) em abril de 20ı6. Durante essa jam de duas horas, i6 estudantes de design de interação e design de jogos de diferentes origens desenvolveram um total de cinco protótipos diferentes para um desafio de rota de fuga em potencial, projetados especificamente em torno das habilidades e possibilidades das formigas.

Durante esta atividade de design, os participantes foram convidados a experimentar a ideia especulativa de ver as formigas como jogadores e projetar um desafio que não fosse muito fácil, e nem muito difícil, para as formigas resolverem. Como esperado, alguns dos designers começaram seu processo de criação concebendo metáforas retiradas do design de jogos com humanos e testando onde elas poderiam se aplicar no design para formigas. Alguns grupos tentaram, em vez disso, visualizar e controlar os efeitos de suas ideias de design projetando quebra-cabeças e progressão de nível enquanto tentavam continuamente especular e discutir como as formigas se apropriariam da mecânica e dos materiais em seus protótipos. As imagens a seguir mostram dois dos protótipos que os designers construíram.

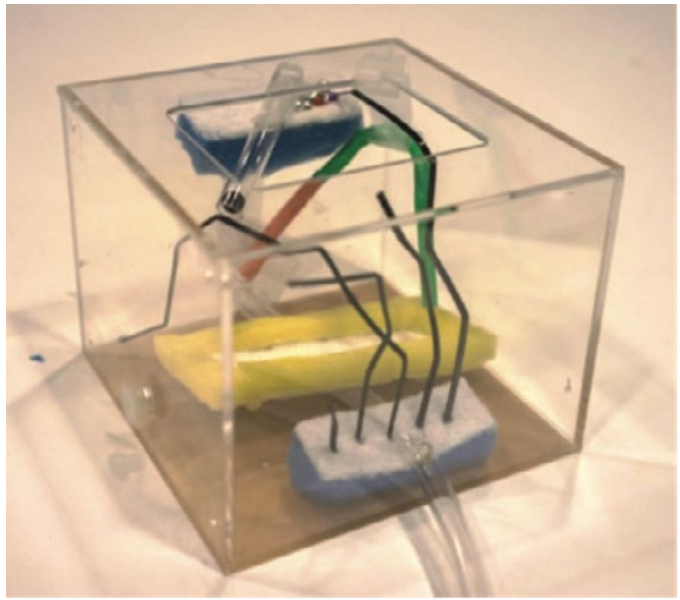

Figura 2. Neste protótipo, os designers (Ralitsa Plamenova Retkova, Simon Nilsson, Eliel Camargo-Molina e Pak Lau) propõem um escape room com três estágios diferentes. Primeiro, as formigas devem escolher o fio correto que leva à próxima área. Em seguida, precisam empurrar uma bola através do tubo transparente. Esta ação irá girar a gangorra, que permitirá que as formigas saiam da sala através do canudo. 


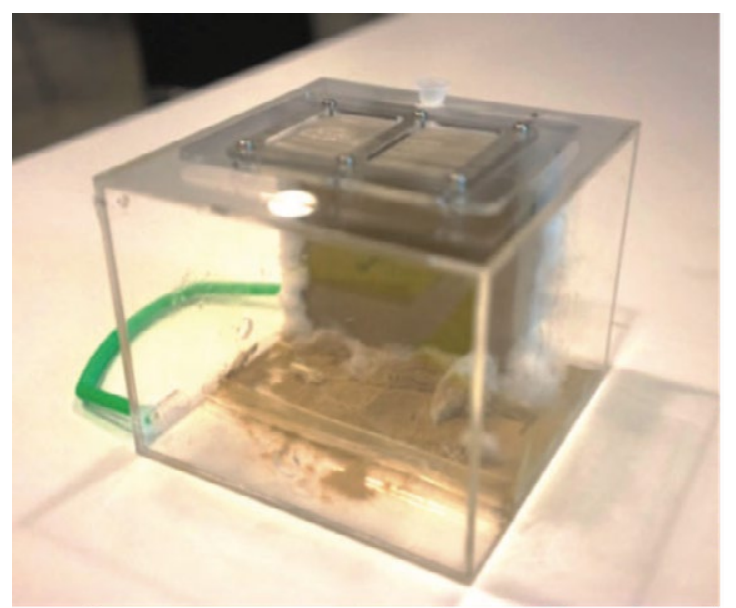

Figura 3. O protótipo nesta imagem, feito por Marian Vijverberg. Nele Schmidt e Koen Wijbrands propõe um escape room no qual as formigas entram em uma pequena sala separada por um papelão. As formigas então têm que rastejar pelo canudo do lado externo da sala para entrar em uma área maior. As formigas podem escapar da sala depois de cruzar um pequeno lago, construindo uma ponte com auxílio de pequenas cordas.

Explicações mais detalhadas de todos os cinco protótipos, bem como os créditos dos outros designers que participaram de sua concepção e montagem, estão disponíveis em: wp.me/p2y7bd-Df.

As mecânicas centradas no jogador que foram propostas através dos diferentes protótipos incluem: caminhar, escalar (em cordas e torres), empurrar, rastejar (através de espaços estreitos, dentro de canudos e tubos), construir (pontes), encontrar (saídas, tubos, becos sem saída), comer (recompensas, obstáculos), equilibrar-se (em cordas finas), escolher (entre diferentes opções de fuga), cruzar (uma gangorra), deslizar (no azeite) e remover (obstáculos).

Além disso, ao final do workshop, todos os i6 designers responderam a uma pesquisa com perguntas abertas sobre suas experiências. Suas respostas ilustraram como quase todos os designers começaram a considerar a possibilidade anteriormente inexplorada de as formigas serem curiosas e talvez até lúdicas. Além disso, os participantes refletiram sobre questões éticas e implicações que devem ser discutidas no caso de intervenções de design que envolvam formigas. Algumas de suas respostas:

“Não deve ser perigoso. Devemos respeitar esses pequenos animais. " (ênfase no original)

"Devemos ter cuidado para não acabar matando-as ou fazendo-as sofrer". 
No entanto, nenhum dos designers considerou a atividade como um exercício eticamente questionável em si, ou se recusou a participar dela, apesar da minha abertura em relação aos sentimentos contraditórios anteriores ao início do game jam. Na mesma pesquisa, os designers foram questionados se esta curta atividade mudou sua visão sobre as formigas ou suas relações com elas:

"Nunca pensei que as formigas pudessem desfrutar de certas atividades, em vez de fazê-las por instinto ou apenas para sobreviver"

"Não... Ou talvez um pouco. Começamos a dar-lhes personalidades."

"Nunca pensei que as formigas fossem lúdicas. Não que eu achasse que não, eu simplesmente não havia pensado sobre isso."

Apesar das diferenças sutis em suas experiências durante o workshop, a maioria dos designers incluiu uma reflexão específica sobre o aumento de sua sensibilidade e interesse pelas formigas que estavam envolvidas neste projeto. Um tópico frequentemente mencionado incluiu a consideração dos designers de formigas sendo talvez "mais lúdicas", "mais espertas" ou "mais curiosas" do que inicialmente esperavam que fossem. Além disso, a maioria dos participantes parecia estar interessada em pensar mais na ideia de que as formigas podem fazer algo, como explorar ou manipular objetos, por razões que não são puramente funcionais ou feitas para a sobrevivência imediata. Essas percepções continuaram sendo um tópico de conversa durante os próximos dias da conferência SIDeR. Além disso, uma pesquisa de acompanhamento enviada seis meses após o game jam gerou dois retornos. Em ambos, os participantes compartilharam como suas experiências mudaram seus encontros com as formigas que encontraram após o game jam e os fizeram sentir mais curiosos e atenciosos com relação às suas vidas. Na próxima fase do projeto, explorei como as formigas interagiam com o protótipo e a resposta que ele gerava.

\section{Fase III: teste de jogos e reflexões ou: como o Twitch encerrou a transmissão ao vivo}

Nesta fase, eu queria completar o ciclo deste projeto e convidei as formigas a reagirem aos projetos que foram criados, observando a interação das formigas com os protótipos. Este processo foi difundido no Twitch e outras plataformas de streaming online com o objetivo de gerar 
conversas e aprofundar as reflexões acerca das ideias propostas. Após o primeiro dia de streaming, a plataforma Twitch fechou a transmissão online da interação das formigas com os protótipos de escape rooms e rotulou como "conteúdo não relacionado a jogos". Este evento gerou sentimentos mistos entre os espectadores que começaram a debater sobre o potencial paradoxo (e a ironia) de projetar escape rooms para animais em cativeiro e o conceito de jogo na sociedade, entendido como uma atividade exclusivamente humana. Essa situação gerou várias discussões online e ilustrou diferentes graus de sensibilidade que as pessoas percebiam em seus relacionamentos com essas formigas ao vê-las interagir com os protótipos. Durante um período de cinco semanas, as formigas interagiram com cada um dos cinco protótipos. Nesse tempo, elas conseguiram escapar de três dos cinco ambientes. Além disso, as formigas criaram uma saída alternativa de seu espaço de convívio, diretamente de seu ninho, contornando o escape room conectado. Depois de alguns testes de protótipo, isso resultou em uma situação em que as formigas entraram em um dos protótipos de escape room do lado de fora do ambiente, "jogando" pelo ambiente ao contrário. No entanto, suas razões para fazer isso, ou suas motivações para interagir com os protótipos, permanecem completamente desconhecidas. Mais detalhes sobre essas fugas, citações de pesquisas e as interações das formigas com cada espaço específico podem ser encontrados online em wp.me/ p2ypbd-eT.

\section{Conclusões}

Neste artigo, segui a noção de Haraway de "conhecimentos situados" e as perspectivas mais amplas de Kohn sobre "selves" como entidades que estão "vivas" e respondem, como uma abordagem básica para o design da mecânica de jogo e interações lúdicas para os animais se apropriarem. Com essa estrutura, pretendo expandir nossa preocupação moral em relação a outros animais e repensar criticamente a atuação de outras entidades em nosso planeta. Especificamente relacionado à discussão sobre a mecânica de jogo, proponho ampliar a definição de mecânica de Sicart (2008) para incluir deliberadamente o design para outros seres que poderiam participar ativamente nos processos de design e responder como jogadores potenciais às interações que criamos. Mais especificamente, sem tomar qualquer posição quanto ao debate se as formigas são jogadores ou não, este projeto de design exploratório com formigas estimulou várias conversas (tanto online quanto pessoalmente) sobre o jogo e a agência do jogador. Sinto que a compreensão atual de jogos como 
design por e para humanos não faz justiça particular ao papel ativo das formigas neste projeto específico. No entanto, sem qualquer informação detalhada das perspectivas das formigas sobre os protótipos, será impossível determinar quaisquer insights relacionados às suas experiências ou compreensão como jogadores ou participantes. No entanto, espero que este projeto ofereça um trampolim inicial para a exploração posterior da noção de formigas (ou outros "selves") como participantes do design e do funcionamento de um jogo e de sua mecânica, sem reduzi-los aos agentes que fazem parte de um sistema de jogo para diversão humana, ou rotulando-os como jogadores no uso convencional (antropocêntrico) do termo.

Ao levar essa estrutura para a prática do design, discuti como o design para (e de alguma forma junto com) formigas gerou novas perspectivas e sensibilidades a respeito de nossos relacionamentos com outros animais. Mesmo que o projeto indiscutivelmente inclua engajamentos "especistas", as reflexões e conversas que surgiram durante e após o experimento de design constituem interpretações fragmentadas, subjetivas e incompletas de insights que foram obtidos durante e após este curto exercício. Como "conhecimentos situados", eles não compartilham simplesmente fatos sobre a vida e o comportamento das formigas; eles também ilustram como o ato de se envolver contextualmente com a vida de outras espécies pode ser um exercício transformador que gera sensibilidade e compaixão para com outras entidades. Este processo foi naturalmente influenciado pelos meus preconceitos e ideologias, à medida que organizei e orientei os diferentes eventos que decorreram. No entanto, é importante notar que as formigas não foram entidades passivas durante o processo: por estarem lá, agindo, escapando, respondendo, se apropriando de artefatos de maneiras inesperadas e interagindo com a mecânica de jogo, elas influenciaram o modo como essas transformações ocorreram e o projeto evoluiu durante todas as três fases do projeto. Argumento que, embora certos tipos de especismo estejam inegavelmente presentes neste projeto, esses tipos de reflexões e sensibilidades não poderiam ser obtidos a "distância", sem praticamente envolver-se com a vida das formigas. Mais especificamente, o desenho deliberado do enquadramento dos encontros com as formigas facilitou um espaço no qual elas eram abertamente convidadas a responder às nossas intervenções. No entanto, olhando para trás, fico imaginando se esses encontros poderiam ter sido enquadrados em torno de um cenário mais igualitário, especialmente no caso de projetos para animais com os quais já nos relacionamos no dia a dia. Em 
outras palavras, outras iterações deste projeto poderiam, talvez, propor um envolvimento melhor com as formigas "selvagens" que encontramos em nossas casas, nos parques que visitamos e nos piqueniques que compartilhamos.

Ao articular e experimentar de forma prática novas perspectivas que combinam noções de mecânica de jogo e "selves", sugiro que esses esforços envolvem apenas um primeiro experimento em abraçar a noção de mecânica de jogo projetada para a experiência do jogador em não-mamíferos. Argumento que a prática do design de jogos que é informada por respostas e apropriações de outras entidades, permite situações inesperadas capazes de estimular novos pensamentos, pontos de vista alternativos e formas de engajamento antes imprevistas que podem direcionar a nossa sensibilidade e compaixão por outros seres que vivem em nosso planeta. Espero que a discussão desta tentativa lúdica de projetar sistemas de jogo e artefatos especificamente para formigas afete seu próximo encontro com esses animais surpreendentemente responsáveis e criativos.

\section{Referências}

Arjoranta, Jonne. Game definitions: A Wittgensteinian approach. The International Journal of Computer Game Research, I4/I, $20 \mathrm{I} 4$.

BATESON, Gregory. Steps to an ecology of mind: collected essays in anthropology, psychiatry, evolution, and epistemology. Northvale, NJ: Jason Aronson Inc., I987.

Buchanan, Richard: Design research and the new learning. Design Issues, I7/4, 200I. p. 3-23

BurghardT, Gordon M. The genesis of animal play: testing the limits. Cambridge, MA: MIT Press, 2006.

Cunningham, Andrew. An actual fish has been playing Pokemon Red for 135 hours now, 20I4. Disponível em: arstechnica.com/gaming/20I4/08/ an-actual-fish-has-been-playing-pokemon-red-for-I35-hours-now. Acesso em: 3 mar. 202I.

Driessen, Clemens; Alfrink, Kars; Copier, Marinka; Lagerweij, Hein; Van Peer, Irene. What could playing with pigs do to us? Antennae: The Journal of Nature in Visual Culture, 30, 2014. p. 79-102.

French, Fiona; Mancini, Clara; Sharp, Helen. Designing interactive toys for elephants. In: Proceedings of CHI Play. ACM Press, 20I5. p. 523528. 
GAVER, William. What should we expect from research through design. In: Proceedings of CHI'12. ACM Press, 20I2. p. 937-946.

Haraway, Donna. Situated knowledges: the science question in feminism and the privilege of partial perspective. Feminist Studies, I4/3, I988, p. 575-599.

Staying with the trouble: making kin in the Chthulucene.

Durham, NC: Duke University Press, 20I6.

HeRTZ, Garnet. Cockroach controlled mobile robot, 2008. Disponível em: conceptlab.com/roachbot. Acesso em: 3 mar. 202I.

Hribal, Jason. Animals, agency, and class: writing the history of animals from below. Human Ecology Forum, I4/I, 2007. p. IOI-II2.

Huizinga, Johan. Homo Ludens: a study of the play-element in culture. Boston, MA: The Beacon Press, I950, I955.

Кон , Eduardo. How forests think: towards an anthropology beyond the human. Oakland, CA: University of California Press, 2013.

LAMERS, Maarten H.; VAN EcK, Wim. Why simulate? hybrid biologicaldigital games. In: Applications of Evolutionary Computation. Springer, 2OI2. p. 2I4-223.

Löwgren, Jonas; Larsen, Henrik S.; Hobye, Mats. Towards programmatic design research. Designs for Learning, 6/I-2, 20I3. p. 80Io०.

Nicholson, Scott. Peeking behind the locked door: a survey of escape room facilities, 2015. Disponível em: scottnicholson.com/pubs/erfacwhite.pdf. Acesso em: 3 mar. 202I.

Salen, Katie; Zimmerman, Eric. Rules of play: game design fundamentals. Cambridge, ma: MIT Press, 2004.

SAvicic, Gordon. Biopong, 2005. Disponível em: yugo.at/processing/ archive /index.php?what=biopong. Acesso em: 3 mar. 202I.

SснӧN, Donald A. Educating the reflective practitioner. San Francisco, CA: Jossey-Bass Publishers, I987.

SiCART, Miguel. Defining game mechanics. The International Journal of Computer Game Research, 8/2, 2008.

Play matters. Cambridge, MA: MIT Press, 2014.

Singer, Peter. Animal liberation. London, uk: The Bodley Head, 2015.

Suchman, Lucy. Located accountabilities in technology production. The Scandinavian Journal of Information Systems, I4/2, 2002, p. 9I-IO5. 
The Roboroach Kickstarter (n.d.): Control a living insect from your smartphone. Disponível em: kickstarter.com/projects/backyardbrains/ the-roboroach-control-a-living-insect-from-your-sm. Acesso em: 3 mar. 2O2I.

WeISBERG, Zipporah. The broken promises of monsters: Haraway, animals and the humanist legacy. Journal for Critical Animal Studies, 7/2, 2009, p. 22-62.

Westerlaken, Michelle. Uncivilizing the future: imagining nonspeciesism. Antae - Special Issue on Utopian Perspectives, 4/I, 20I6. p. $53-67$.

Westerlaken, Michelle; Gualeni, Stefano. Felino: the philosophical practice of making an interspecies videogame. In: Proceedings of the 8th Philosophy of Computer Games Conference, 20I4. p.I-I2.

Becoming with: towards the inclusion of animals as participants in design processes. In: Proceedings of ACI'16. ACM Press, 20I6. p. I-Io. Wirman, Hanna. Games for/with strangers - Captive orangutan (pongo pygmaeus) touch screen play. Antennae: the journal of nature in visual culture, 30, 20I4. p. IO3-II2.

Wirman, Hanna; Jörgensen, Ida K.H. Designing for intuitive use for non-human users. In: Proceedings of ACE'15. ACM Press, 20I5. p. I-8. 